\title{
Narrativas de éxito y fracaso: autoridades indígenas de frontera y usos sociales del pasado en Chiapa de la Real Corona [1571-1603]
}

Resumen: Este artículo estudia los usos del pasado en las narrativas de éxito y fracaso de las autoridades indígenas de Chiapa entre 1571 y 1603. Con base en el análisis de litigios por tierras y probanzas de méritos, se explica que los discursos de los chiapanecas buscaron revertir las categorías de "conquistados", "indios de guerra", "advenedizos" y "extranjeros", para ello, aludieron a formas de expresión hispanizadas para distinguirse de los indios del "común". Las narraciones sobre el pasado vertidas en la documentación fueron resultado de la reconfiguración social de los pueblos de indios debido a los conflictos para acceder a los cargos de república y a las tierras de comunidad.

Palabras clave: usos sociales de la memoria, autoridades indígenas, conflictos sociales, categorías sociales, frontera.

\section{Narratives of success and failure: indigenous border authorities and social uses of the past in Chiapa de la Real Corona [1571-1603]}

Abstract: This article studies the past uses in the indigenous authorities narratives' of success and failure at Chiapa between 1571 and 1603. Based on the analysis of land litigation and proofs of merits, it explained that the discourses of the Chiapan people sought to reverse the categories of "conquered," "war Indians," "upstarts," and "foreigners." They alluded to Hispanicized forms of expression to differentiate themselves from the "common" Indians. The past narratives were resultant from the social reconfiguration of the Indian villages due to the conflicts to access the republic and community lands' positions.

Keywords: social uses of memory, indigenous authorities, social conflicts, social categories, borderland.

\section{Narrativas de sucesso e fracasso: autoridades indígenas de fronteira e usos sociais do passa- do em Chiapa de la Real Corona [1571-1603]}

Resumo: Este artigo estuda os usos do passado nas narrativas de sucessos e fracassos das autoridades indígenas do Chiapan entre 1571 e 1603. A partir da análise de disputas de terras e de provas de mérito explica-se que os discursos dos chiapanecas buscaram reverter as categorias de "conquistados", "índios de guerra", "forasteiros" e "estrangeiros". Para tanto aludiam a formas de expressão hispanizadas, para se distinguir dos índios "comuns". As narrativas sobre o passado expressas na documentação foram fruto da reconfiguração social dos povos indígenas, em decorrência dos conflitos pelo acesso a cargos de república e terras comunitárias.

Palavras-chave: usos sociais da memória, autoridades indígenas, conflitos sociais, categorias sociais, fronteira.

Cómo citar este artículo: Martha Atzin Bahena Pérez, "Narrativas de éxito y fracaso: autoridades indígenas de frontera y usos sociales del pasado en Chiapa de la Real Corona [1571-1603]", Trashumante. Revista Americana de Historia Social 19 [2022]: 28-49.

DOI: 10.17533/udea.trahs.n19a02

Fecha de recepción: 9 de abril de 2021

Fecha de aprobación: 5 de octubre de 2021

Martha Atzin Bahena Pérez: Doctora, maestra y licenciada en Historia por la Universidad Nacional Autónoma de México. Profesora de la misma universidad. ORCID: 0000-0003-1025-2976.

Correo electrónico: atzinbp@comunidad.unam.mx 


\title{
Narrativas de éxito y fracaso: autoridades indígenas de frontera y usos sociales del pasado en Chiapa de la Real Corona [1571-1603] ${ }^{\star}$
}

\author{
Martha Atzin Bahena Pérez
}

finales del siglo XVI y principios del XVII, algunos indios del pueblo de
Chiapan que habían participado en la pacificación de Lacandón, Pochutla y
Topiltepeque solicitaron que no se les cobrara el tributo y se les dejara utilizar
caballos y armas, con el argumento de que sus acciones defendían el reino
(Figura 1). ${ }^{1}$ Algunos chiapanecas se asumieron como vasallos del rey y se valieron
de la justicia real para legitimarse frente a otros pueblos y distinguirse socialmente
respecto de sus propios gobernados. Para ello, en las comunicaciones que entablaron

* Investigación realizada gracias a los proyectos "Reversing the Genealogies of Unsuccess, 16th19th Centuries" (Marie Skłodowska-Curie Grant Agreement n. 823998) e "Iberoamérica global. Personas, saberes y cosas de las Indias Occidentales en el mundo. Siglos XVI al XVIII" (PAPIITUNAM IN-403720).

1. El pueblo de Chiapan se puede ubicar en el actual Chiapa de Corzo, al norte de la depresión central del estado de Chiapas. A este pueblo, por ser el más numeroso, también se le llamó Chiapa de Indios, al compararlo con Chiapa de españoles, que era la ciudad hispana llamada Ciudad Real. Según Peter Gerhard, los españoles llamaron a los indios que habitaban en Chiapan como chiapanecas por deformación del náhuatl. Véase Peter Gerhard, La frontera sureste de la Nueva España (México: Universidad Nacional Autónoma de México, 1991) 115. Jan de Vos afirma que los mercaderes y soldados mexicas, quienes navegaban por el Grijalaba para llegar a Guatemala, los llamaron así porque en la zona de Chiapan se sembraba la chía.Véase Jan de Vos, La batalla del Sumidero. Historia de la rebelión de los chiapanecas, 1524-1534, a través de testimonios españoles e indígenas (México: Instituto Nacional Indigenista / Consejo Nacional para la Cultura y las Artes, 1990) 25. Este autor manifestó que los chiapanecas se llamaban a sí mismos Napinoka o Napijuá-yaka.Véase Jan deVos, Vivir en frontera. La experiencia de los indios de Chiapas (México: Centro de Investigaciones y Estudios Superiores en Antropología Social / Instituto Nacional Indigenista, 1997) 46. Debido a que Chiapan se localizaba en un río, sus pobladores tenían condiciones óptimas para la agricultura y para la comunicación con otras regiones. Además, se localizaban en una importante ruta comercial prehispánica. Véase Gudrun Lenkersdorf, Génesis histórica de Chiapas 1522-1532. El conflicto entre Portocarrero y Mazariegos (México: Universidad Nacional Autónoma de México, Instituto de Investigaciones Filológicas, 1993) 24. Se ha planteado que para los siglos XVI y XVII el pueblo de Chiapan fue el más numeroso de toda la provincia.Véase Mario Humberto Ruz Sosa, Mohonyhovi. Sanctissima Trinidad... Chiapa y su Cofradía de la Vera Cruz al mediar el siglo XVII (México: Universidad Nacional Autónoma de México, Instituto de Investigaciones Filológicas, 2020) 9-10. 
con la autoridad real (probanzas de méritos y litigios de tierras) emplearon una retórica que articulaba sus antigüedades prehispánicas con su participación en las "conquistas" y la "pacificación". Fue así como, en ese contexto de conflicto, los chiapanecas "pacificadores" crearon una memoria social del pasado ${ }^{2}$ para

Figura 1. Mapa de la provincia de Chiapa y Pochutla Lacandón [zona de frontera], siglo XVI.

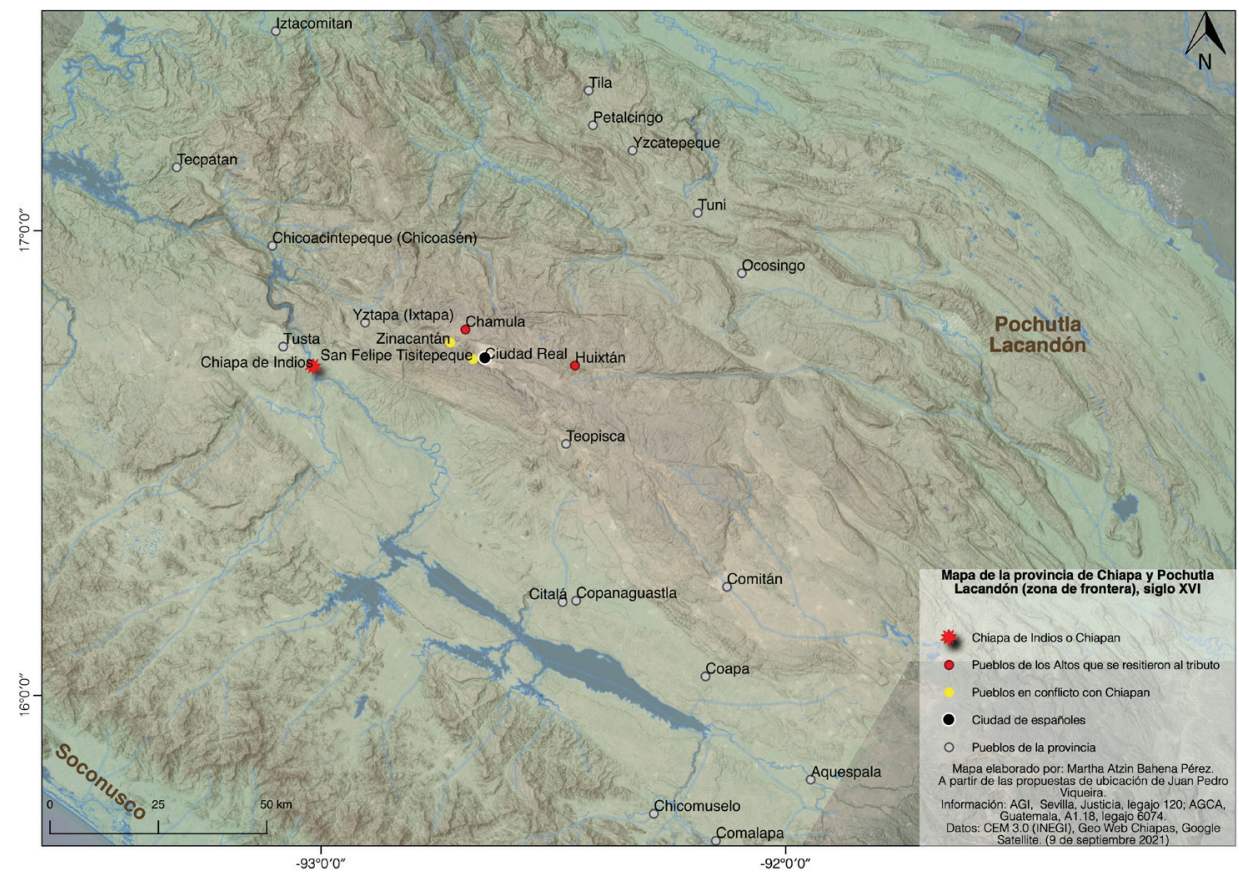

Fuente: elaboración propia a partir de:AGI, Sevilla, Justicia, leg. 120; AGCA, Guatemala, A1.18, leg. 6074 y las propuestas de ubicación de Juan Pedro Viqueira.

2. El concepto "uso social del pasado" ha sido planteado por la historia social de la memoria. Algunos de estos historiadores han discutido o tomado como referente la obra del sociólogo Maurice Halbwachs.Véase Maurice Halbwachs, Les cadres sociaux de la mémoire (París: Librairie Félix Alcan, 1925); Maurice Halbwachs, La memoria colectiva (Zaragoza: Prensas Universitarias de Zaragoza, 2004). Entre los primeros está Marc Bloch, quien cuestionó en 1925 la separación tajante entre colectividad e individualidad y viceversa. Además, este autor planteó que la costumbre jurídica también forma parte de la memoria colectiva. Véase Marc Bloch, Historia e historiadores (Madrid: Akal, 2008) 223-232. Sobre los segundos, véase Pierre Nora, Les lieux de mémoire (Montevideo: Ediciones Trilce, 2008). A su vez, el trabajo de Pierre Nora ha sido cuestionado por Peter Burke, quien ha manifestado que no hay un nítido contraste entre la transformación escrita de la memoria y la tradición oral de ella, pues ambas tienen sus "propias formas de estilización". Véase Peter Burke, Formas de historia cultural (Madrid: Alianza Editorial, 2000) 70. Un análisis historiográfico completo sobre estas obras puede verse en: Hernán Sorgentini, "Reflexión sobre la memoria y autorreflexión de la historia", Revista Brasileira de História 23.45 (2003): 103128. Un nuevo estudio es el de Josefa Viegas que ha hablado de los usos sociales del pasado en contextos específicos. Véase Josefa Viegas, "Memoria e historia. Los usos sociales del pasado", Teoría y Praxis 10 (2007): 109-121. 
reafirmarse como vasallos y súbditos del rey, y revertir las narrativas que tenían de ellos sus contrincantes. ${ }^{3}$

El objetivo de este artículo es estudiar los usos del pasado ${ }^{4}$ que hicieron algunos chiapanecas de manera grupal e individual para distinguirse de las categorías de "indios de guerra", "advenedizos" y "extranjeros" que se imputaban al pueblo de Chiapan. Al respecto, es importante puntualizar que estas narrativas fueron producto de conflictos sociales en los que los indios se apropiaron de las prácticas jurídicas hispánicas para defenderse en los tribunales de justicia. ${ }^{5}$

En primer lugar, se explicará el modo en que los conquistadores hispanos produjeron dos categorías sociales para referirse a los indios: "de paz" y "de guerra". Ello se observa en la descripción del escudo de armas de la Villa de San Cristóbal de las Casas, así como en los testimonios de litigios por encomiendas de los años 1528 a 1534. En segundo lugar, se analizarán las categorías de “advenedizos” y “extranjeros" que se encuentran en el pleito por las salinas de Ixtapa entre el pueblo de Zinacantán y el de Chiapan. Para ello, se contextualizará el conflicto durante la conformación de las repúblicas de indios. En tercer lugar, se hará un análisis de las narrativas de éxito en los méritos y servicios de algunos indios, quienes enunciaron sus servicios en la "conquista” y "pacificación” de Lacandón.

\section{La guerra como productora de categorías sociales}

Al fundarseVilla Real en 1528, los indios de Chiapan, Zinacantán, Chamula y Huixtan se refugiaron en las montañas y dejaron sus pueblos desiertos. ${ }^{6}$ En un principio, los mercaderes zinacantecos y chiapanecos se aliaron al capitán Diego de Mazariegos con el objetivo de mantener el control de las rutas comerciales que administraban desde tiempos anteriores a la llegada de los españoles. ${ }^{7}$ Aunque la coalición entre

3. Un trabajo parecido ha sido realizado por Laura E. Matthew para Guatemala, quien se enfocó en la memoria social de los indígenas conquistadores que se asentaron en CiudadVieja provenientes del centro de México y Oaxaca. Matthew estudia no solo sus probanzas de méritos y servicios, sino también la representación de aquellos discursos en diversos códices, lienzos, mapas, títulos festividades y rituales. Véase Laura E. Matthew, Memorias de conquista. De conquistadores indígenas a mexicanos en la Guatemala colonial (Puebla / Tlaxcala / Ciudad de Guatemala: Instituto de Ciencias Sociales y Humanidades “Alfonso Vélez Pliego", Benemérita Universidad Autónoma de Puebla / Sociedad de Geografia, Historia, Estadística y Literatura del Estado de Tlaxcala / Centro de Estudios Urbanos y Regionales, Universidad de San Carlos Guatemala, 2017) 7-10.

4. Burke 69.

5. Estas se entienden como narrativas colectivas. Véase Frederick W. Mayer, Narrative Politics. Stories and Collective Action (Oxford: Oxford University Press, 2014) 30-31.

6. La primera villa de españoles establecida en los Altos de Chiapas se nombró Villa Real. Posteriormente cambió su nombre a San Cristóbal de los Llanos. A la llegada del cuarto grupo de conquistadores, Enríquez de Guzmán le cambió el nombre aVilla Viciosa. Cuando Pedro de Alvarado tomó posesión de su gobierno, regresó el nombre de San Cristóbal de los Llanos a la villa. Finalmente, en 1536, obtuvo el nombramiento de ciudad y volvió a cambiar su nombre a Ciudad Real.

7. Ello estuvo relacionado con que las rutas comerciales prehispánicas eran las mismas que las rutas 
indios mercaderes e hispanos se mantuvo, la villa española impuso el tributo y sus habitantes hurtaban las milpas de los pueblos. Los habitantes de Chiapan y Zinacantán prefirieron huir a las montañas para evadir el pago del tributo. ${ }^{8}$

La nueva villa necesitaba medios de sustento, por lo que los mercaderes y las huestes de Mazariegos fueron tras los indios que se habían ido a las montañas. Así, una oleada de violencia contra la población y los principales de Chiapan y Zinacantán se traslució en denuncias que daban cuenta de cómo las autoridades indígenas de los pueblos fueron aperreadas, ahorcadas y asesinadas. En cambio, los indios mercaderes fueron reconocidos por los españoles, quienes los llamaron "caciques", 9 al considerarlos como "indios de razón" e "indios de paz", y contraponerlos con los "indios de guerra" que no querían tributar.

Ahora bien, el modo en que se formulaban estas categorías, al ser producto de conflictos sociales, ${ }^{10}$ puede observarse en la documentación elaborada por los españoles. Por ejemplo, Bernal Díaz del Castillo calificó a los mercaderes zinacantecos como gente de razón, con base en su experiencia durante las jornadas de los vecinos de la Villa del Espíritu Santo que iban a los Altos de Chiapa por esclavos u otros tributos. ${ }^{11}$ Además de dotar a los conquistadores de tamemes, de esclavos capturados y alimentos, los zinacantecos fungían como sus guías en las expediciones.

Por otro lado, los participantes en los actos represivos contra los refugiados en las montañas en 1528 justificaron su acción al expresar que los indios eran "bellacos", ${ }^{22}$

de las jornadas de conquista, por lo que los mercaderes buscaban mantener su control. Véase Laura E. Matthew y Michel R. Oudijk, eds., Indian Conquistadors. Indigenous Allies in the Conquest of Mesoamerica (Norman: University of Oklahoma Press, 2012) 49 y 57.

8. Durante la época prehispánica la dominación mexica solo había llegado al Soconusco en donde cobraban tributo, pero este grupo no logró conquistar las poblaciones asentadas en los Altos de Chiapas por lo que a diferencia del centro de México, los indios de esta región no estaban acostumbrados a tributar. Véanse Murdo J. Macleod, Historia socio-económica de la América Central Española, 1520-1720 (Guatemala: Editorial Piedra Santa, 1980) 34; Lenkersdorf, Génesis histórica; De Vos, Vivir en frontera.

9. Gudrun Lenkersdorf ubicó que desde 1532 los españoles nombraron a los primeros caciques en el pueblo de Chiapan, lo que no se extendió a todos los pueblos mayas de la provincia en donde se nombraron gobernadores indígenas. La misma autora plantea que el término cacique viene de la lengua taína.Véase Gudrun Lenkersdorf, Repúblicas de indios. Pueblos mayas en Chiapas, siglo XVI (México: Plaza y Valdés, 2010) 79.

10. Véase Antonio Manuel Hespanha, "Categorias. Uma reflexão sobre a prática de classificar", Análise Social 38.168 (2003): 828.

11. Bernal Díaz del Castillo, Historia verdadera de la conquista de la Nueva España (Manuscrito Guatemala), ed.José Antonio Barbón Rodríguez (México: El Colegio de México / Universidad Nacional Autónoma de México / Servicio Alemán de Intercambio Académico, 2005) 587.

12. Según el diccionario de autoridades, el concepto de "bellaco" se le daba al "hombre de ruines y malos procederes, y de viles respétos, y condición perversa y dañada [...] la sacan del nombre Villa, ò Villáno, porque los villanos naturalmente suelen ser de baxos y viles pensamientos [...]". También se consideraba lo bellaco como algo malo, perverso y ajeno de razón. Diccionario de Autoridades, t. 1 (Madrid: Real Academia Española, 1726). https://webfrl.rae.es/DA.html (02/03/2021). 
por lo que tenían que hacerles la guerra para que sirvieran a la Corona. ${ }^{13}$ También decían que los indios no buscaban "hacer por bien cosa alguna sin que primero sean atemorizados por cruel guerra, e muchas bezes han estado de paz e sujetos e se tornan a rebelar". ${ }^{14}$ Es decir, que no cumplían con las negociaciones que tenían con los españoles, por lo que tacharon de traidores a quienes solo por la guerra serían "pacificados". Por otro lado, también se habló sobre la organización política de los indios, al decir que eran "mala gente e sin razon por que no tienen señor ni cabildo que los mande, e que sabe que han estado de paz e se han rebelado". ${ }^{15}$ De esta manera, los españoles identificaban a los indios de razón como aquellos con quienes se podía negociar.

Ahora bien, mientras que "indios de paz" era una categoría que los españoles utilizaban en su documentación para mostrar al rey los éxitos de sus conquistas, "los indios de guerra" y sus alzamientos formaban parte de las dificultades que enfrentaban para mantener su dominio sobre los pueblos. Los discursos de los conquistadores buscaban persuadir a las autoridades reales sobre la necesidad de obtener recompensas al esclavizar a los llamados "indios rebeldes" a cambio de los servicios que hacían al rey y los peligros que enfrentaban. ${ }^{16}$

Posteriormente, entre 1532 y 1534, según la documentación producida por los españoles avecindados en San Cristóbal de los Llanos, el pueblo de Chiapan volvió a rebelarse. Esta vez adujeron la gran explotación que padecían en la extracción de oro y la situación insalubre de los lavaderos donde trabajaban. Dejaron nuevamente el pueblo y se refugiaron en el Cañón del Sumidero, un sitio de difícil acceso.

Sin embargo, los españoles reprimieron las nuevas sublevaciones con la ayuda de los indios mercaderes de Chiapan, junto a los mexicas y tlaxcaltecas que formaban parte de sus expediciones. En las fuentes sobre estos acontecimientos, las categorías iniciales para referir a indios de paz o de guerra dieron paso al adjetivo de "indios rebeldes", quienes debían regresar a la obediencia con la acción pacificadora de los españoles. El matiz era decisivo para legitimar el asiento de los conquistadores, convertidos en vecinos que establecían la ley del rey en las nuevas tierras.

13. "Testificación del vecino Juan de Herrera en el pleito por la encomienda de Zinacantán entre Francisco Marmolejo y Pedro de Estrada", Ciudad Real de Chiapa, 1535. AGI, Sevilla, Justicia, leg. 120 , exp. 1, f. 35 .

14. "Testificación del vecino Alonso de Vargas en el pleito por la encomienda de Zinacantán entre Francisco Marmolejo y Pedro de Estrada", Ciudad Real de Chiapa, 1535. AGI, Sevilla, Justicia, leg. 120 , exp. 1, f. 35 .

15. "Testificación del vecino Diego Calbache en el pleito por la encomienda de Zinacantán entre Francisco Marmolejo y Pedro de Estrada", Ciudad Real de Chiapa, 1535. AGI, Sevilla, Justicia, leg. 120 , exp. 1 , f. 35 .

16. Sobre la "guerra justa" para hacer esclavos a los indios hubo una gran discusión entre tratadistas, conquistadores y frailes. Desde 1519, los conquistadores que llegaron con Hernán Cortés a Veracruz solicitaron al rey hacer esclavos a los indios que no querían servir ni tributar, pues argumentaron que necesitaban sobrevivir en las nuevas tierras y no tenían para comer. De esta forma, los conquistadores comenzaron a herrar esclavos, primero para su subsistencia y después como negocio.Véase Silvio Zavala, Los esclavos indios en Nueva España (México: El Colegio Nacional, 1967) 1. 
En el escudo de armas que envió el rey Carlos V en 1535 a la provincia de Chiapa se rememoró la forma en que los vecinos españoles y los "indios amigos" reprimieron violentamente a quienes huyeron al Cañón del Sumidero para no pagar el tributo, uno de los sitios de más difícil acceso para los españoles. Esta represión quedó cristalizada en la descripción del escudo de armas de la Villa de San Cristóbal, en el cual se dibujaron dos leones rampantes sobre las dos sierras del Cañón del Sumidero, que representaban los espacios naturales donde los indios se escondían de los españoles y en los que realizaban sus rituales religiosos. Uno de aquellos leones tenía una palma que, al simbolizar al santo de los viajeros, San Cristóbal, representaba a los vecinos de la ciudad española. El otro tenía un castillo que simbolizaba la autoridad del rey de España. Asimismo, el cielo rojo del escenario aludía a la violenta represión. ${ }^{17}$

El escudo de armas cristalizó el triunfo de los vecinos españoles como representantes de la jurisdicción real. La merced de aquella distinción presentada en Chiapa de Indios, mediante la cooperación de los indios mercaderes ilustró el fracaso de los rebeldes del pueblo de Chiapan, quienes al huir intentaron evadir el cobro del tributo y las arbitrariedades de los invasores. De esta manera, desde la perspectiva de la nueva ley, la resistencia era el principio por donde se iba al fracaso.

En la medida que las primeras autoridades indígenas de Chiapan promovieron aquella resistencia, el conjunto de la población fue marcado con el signo de la desobediencia. Ello presentó un problema para los mercaderes indígenas colaboradores que formaron parte de las huestes "pacificadoras". Si su permanencia como nuevas autoridades del pueblo durante el siglo XVI inclinó la balanza a favor del dominio español, paradójicamente, también los vinculó al pasado colectivo que marcó a aquel pueblo. Así, los descendientes de aquellos colaboradores buscaron distinguirse de los indios del "común", a quienes se imputaba que no siempre estuvieran de paz. Para ello escribieron probanzas de méritos y servicios en los que se presentaron como conquistadores, tal como hicieron mexicas y tlaxcaltecas, con el objetivo de obtener mercedes reales y otros privilegios que los distinguieran.

\section{2. “Gente advenediza y extranjera”: categorías sociales en el pleito por tierras entre Chiapan y Zinacantán}

Un elemento central del proceso de consolidación de la monarquía española en América fue la formación de repúblicas de indios. ${ }^{18}$ En la provincia de Chiapa lograron instaurarse efectivamente hasta la década de los setenta del siglo XVI. ${ }^{19}$ Esto

17. "Escudo de armas a San Cristóbal de los Llanos", villa de Madrid, 1 de marzo de 1535. ADA, Madrid, Escudos de Armas, caja 238, exp. 27. copia en: AGI, Sevilla, Audiencia de Guatemala, leg. 393, exp. 1, ff. 121v-122.

18. Sobre la formación de repúblicas de indios desde una perspectiva comparada, véase Margarita Menegus Bornemann, "El gobierno de los indios en la Nueva España, siglo XVI. Señores o cabildo", Revista de Indias 59. 217 (1999): 599-617.

19. Sobre la formación de Repúblicas de Indios en la provincia de Chiapa, véase Lenkersdorf, 
trajo consigo dos cambios, uno respecto a la definición de quién podía ser autoridad india, y otro respecto al papel legitimador de la autoridad real en la definición de la propiedad de la tierra. El primero abrió la posibilidad de que nuevos indios accedieran a los cargos de república. Así, quienes habían sido caciques y señores por sus alianzas con los conquistadores y encomenderos vieron mermado su poder debido a la incorporación de nuevos regidores que procedían de familias ajenas a los primeros aliados indígenas. El segundo derivó de pleitos por los límites de la propiedad comunal y la explotación de recursos naturales entre distintas repúblicas de indios. ${ }^{20}$ Así ocurrió en junio de 1571 entre Chiapan y Zinacantán, cuando el primero demandó al segundo y su sujeto San Felipe Tisitepeque por la posesión de las salinas de Iztapa, sobre las cuales aseguraban que les pertenecían legítimamente "de tanto tiempo acá por memoria de hombres". ${ }^{21}$

Para legitimar la posesión de sus territorios y el derecho a explotar sus recursos, aunque los representantes de uno y otro pueblo formularon narrativas en las que referían tanto el pasado prehispánico como la colaboración con los españoles, su argumento principal se fundaba en el usufructo que ejercían en ese momento. Para ello, invocaban títulos certificados por autoridades reales, por los que, en última instancia, el rey reconocía la posesión. Los indios y sus procuradores vieron la importancia de aludir al usufructo de las tierras desde tiempos remotos porque las autoridades reales reconocían esta posesión mientras se apropiaban del dominio eminente en nombre del rey. ${ }^{22}$ Como se expone enseguida, recurrir al pasado prehispánico y a la colaboración en las conquistas constituía un uso social y jurídico que condicionaba la memoria a las necesidades del presente.

Tanto los chiapanecas como los zinacantecos fueron representados por un procurador o defensor de indios. ${ }^{23}$ Los primeros, por Juan Martínez de la Torre, quien había sido administrador del ingenio la Vega y cobrador de tributo del pueblo de

Repúblicas de indios.

20. Sergio Eduardo Carrera Quezada, "Las composiciones de tierras en los pueblos de indios en dos jurisdicciones coloniales de la Huasteca, 1692-1720", Estudios de Historia Novohispana 52 (2015): 32; Sergio Eduardo Carrera Quezada, Sementeras de papel. La regularización de la propiedad rural en la Huasteca Serrana, 1550-1720 (México: El Colegio de México / Centro de Investigaciones y Estudios Superiores en Antropología Social, 2018) 129.

21. "Extracto de un título antiguo de Chiapa de los indios, probando su antigüedad y legitimidad de posesión de tierras", Ciudad Real de Chiapa, 6 de junio de 1571. AGCA, Guatemala, Fondo Tierras, A1.18, leg. 6074, exp. 54880, f. 1. Con base en esta documentación los trabajos arqueológicos sobre los Altos de Chiapas y la Meseta Central Chiapaneca han concluido que este pleito habría comenzado desde tiempos prehispánicos. Véase Carlos Alberto Navarrete Cáceres, The Chiapanec History and Culture (Provo: Brigham Young University, 1966).

22. Mariano Peset y Margarita Menegus Bornemann, "Rey propietario o rey soberano", Historia Mexicana 43.4 (1994): 564.

23. Sobre la figura de defensor de indios, véase Caroline Cunill, Los defensores de indios de Yucatán y el acceso de los mayas a la justicia colonial, 1540-1600 (Mérida: Centro Peninsular en Humanidades y Ciencias Sociales / Universidad Nacional Autónoma de México, 2012). 
Chiapan cuando este formaba parte de la encomienda de Baltasar Guerra. ${ }^{24}$ Por su parte, Luis de Estrada representó a los de Zinacantán, pues era hijo del primer poblador, Pedro de Estrada, a quien el capitán Diego de Mazariegos otorgó la encomienda de Zinacantán. ${ }^{25}$ Así, en la defensa de sus propios intereses, el cobrador de tributo de Chiapan y el encomendero de Zinacantán ofrecieron argumentos jurídicos en los que traslucían los de sus representados.

Cada parte fundamentó su derecho al usufructo de las salinas, único y principal argumento, con narrativas sobre lo ocurrido en el pasado. Así, la parte de los indios zinacantecos esgrimió que, tras la ausencia de los contrarios cuando se alzaron “contra los españoles" en el Cañón del Sumidero y se ausentaron de su pueblo por cuatro años, dejaron las tierras "solas y desamparadas", por lo que "los pueblos de Zinacantán y San Felipe y otros comarcanos" comenzaron a cultivarlas. ${ }^{26}$

Por su parte, el pueblo de Chiapan argumentó que, en 1546, ante el alcalde ordinario de Ciudad Real Pedro de Solórzano, ya habían litigado con los zinacantecos los límites territoriales de sus pueblos, de lo que resultó que las tierras pertenecían a los indios de Chiapan por vista de ojos. La resolución del juez de república habría sido confirmada por el juez visitador Gonzalo Hidalgo de Montemayor en 1549. ${ }^{27}$ Los límites autorizados incluían las salinas, pero los chiapanecas denunciaban que Zinacantán y San Felipe no acataron el resolutivo. Mientras los de Zinacantán y Tisitepeque aludieron a la posesión de las tierras fundada, en última instancia, en la ausencia causada por la rebeldía de los chiapanecas, estos invocaron los títulos otorgados por el cabildo de Ciudad Real y refrendados por la autoridad real. Ambos pueblos hicieron uso de los referentes jurídicos hispanos sobre el derecho a usufructuar las salinas.

Para reforzar su posición, Luis de Estrada, encomendero y procurador de Zinacantán, San Felipe e Iztapa, opuso otro argumento. Al tiempo que imputó falsedad en la demanda de los chiapanecos y su procurador, alegó que los zinacantecos tenían mucho más tiempo en la región y que los chiapanecas no tenían derecho al uso "por ser como eran gentes advenedizas y no ser suyas las dichas tierras y, ser gentes extranjeras [...] naturales de la Provincia de Nicoya [San Miguel Nicaragua]

24. "Informaciones de Juan Martínez", Santiago de Guatemala, 3 de agosto de 1547. AGI, Sevilla, Audiencia de Guatemala, leg. 110, exp. 34. Cuando el pueblo pasó a cabeza de la Real Corona, en 1552, Juan Martínez continuó cobrando el tributo, ahora para llevarlo a la Caja Real de Santiago de Guatemala, ya que tejió buenos lazos con los caciques del pueblo, como Diego Nocayola y su hijo Luis de León. "Probanza de méritos y servicios de Juan Martínez de la Torre", Santiago de Guatemala, 3 de marzo de 1570. AGI, Sevilla, Audiencia de Guatemala, leg. 53, f. 4.

25. Por esta razón, Francisco Marmolejo, avecindado en Espíritu Santo, pleiteó la encomienda de Zinacantán con Pedro de Estrada padre. "Pleito por la encomienda de Zinacantán entre Francisco Marmolejo y Pedro de Estrada”, Santiago de Guatemala, 1535. AGI, Sevilla, Justicia, leg. 120, exp. 1.

26. "Extracto de un título antiguo", f. 2 v.

27. "Extracto de un título antiguo", f. 2v. El visitador fue enviado por Alonso López Cerrato, presidente de la Real Audiencia de los Confines, para liberar a los indios esclavos. Véase "Luis Mazariegos, vecino de Chiapa, con Luis de Luna vecino de Córdoba, sobre cobranza de una cantidad de pesos", Santiago de Guatemala, 1551, AGI, Sevilla, Justicia, leg. 1032, exp. 8, ff. 11-13. 
que eran trescientas leguas de la dicha Provincia de Chiapa". ${ }^{28}$ Estrada invocaba así una condición que tenía implicaciones específicas fundadas en el derecho natural y común, y que en el momento del pleito guardaba relación con las denuncias sobre "extranjeros" que se avecindaban en las ciudades del reino de Guatemala.

Vale la pena detenerse en las categorías de "advenedizo" y "extranjero". Ambas estaban relacionadas entre sí. ${ }^{29}$ Para la época de la configuración de repúblicas de indios se consideraba como "advenedizos" a quienes no pertenecían a las familias de gobernantes prehispánicos que ocupaban cargos de república. ${ }^{30}$ Es probable que los zinacantecos consideraran como "advenedizos" a los caciques chiapanecas por haber sido nombrados por su primer encomendero, Baltasar Guerra, y después por los frailes dominicos. ${ }^{31}$

La distinción de "extranjeros" era muy común en la zona, pues la Casa de Contratación perseguía a genoveses, venecianos y portugueses que se avecindaban en el reino de Guatemala, al que se adscribía la provincia de Chiapa. ${ }^{32}$ Además, desde la perspectiva de las autoridades reales, los “extranjeros” también eran enemigos de la

28. "Extracto de un título antiguo", f. 3v.

29. Según el Diccionario de Autoridades, "advenedizo" era la persona "extrangéra, ò forastéra, que de tierras y Réinos extraños viene à las nuestras: lo que mas regularmente se entíende de la gente plebeya y común, que sin empléo, dignidad, ú oficio, sino solo por vagar, ò buscar la vida se vienen à nuestras tierras". También se llamaba así "a los que de la gentilidad, ò la secta de Mahoma se convierten à nuestra Santa Fé”. Diccionario de Autoridades, t. 1 (Madrid: Real Academia Española, 1726). https://webfrl.rae.es/DA.html (02/03/2021).

30. Al respecto véase Menegus Bornemann, "El gobierno de los indios".

31. Véase Lenkersdorf, Repúblicas de indios; Martha Atzin Bahena Pérez, "La participación de frailes dominicos en la rebelión chiapaneca de 1547", De Mérida a Taguzgalpa. Seráficos y predicadores en tierras mayas, chiapanecas y xicaques, coord. José Manuel A. Chávez Gómez (México: Secretaría de Cultura / Instituto Nacional de Antropología e Historia, 2017) 121-140.

32. Sobre el concepto de "extranjero" en la monarquía de España y específicamente en el mundo indiano hay una vasta historiografia. Entre los primeros trabajos al respecto se encuentran los de Tamar Herzog, "Naturales y extranjeros: sobre la construcción de categorías en el mundo hispánico", Cuadernos de Historia Moderna, Anejo 10 (2011): 21-31, doi: rev_CHMO.2011.38668; María Inés Carzolio, "En los orígenes de la ciudadanía en Castilla. La identidad política del vecino durante los siglos XVI y XVII", Hispania 62.211 (2002): 637-691, doi: 10.3989/hispania.2002.v62.i211.262. Recientemente se han publicado trabajos enfocados en América como los estudios de caso de Gleydi Sullón Barreto, Extranjeros integrados. Portugueses en la Lima virreinal, 1570-1680 (Madrid: Consejo Superior de Investigaciones Científicas, 2016); específicamente sobre el reino de Guatemala, véase Martha Atzin Bahena Pérez, "El mundo en el reino de Guatemala: 'extranjeros', arraigo y cohesión social 1535-1630", Tiempos Modernos 11.42 (2021): 220-237. También se han publicado compilaciones como la de Fernando Ciaramitaro y José de la Puente Brunke, coords., Extranjeros, naturales y fronteras en la América Ibérica y Europa (14921830) (México / Murcia: Universidad Autónoma de la Ciudad de México / Editorial de la Universidad de Murcia / Red Columnaria, 2017). Debido a la cantidad de trabajos inspirados en los estudios de Tamar Herzog, recientemente esta historiadora publicó un artículo en el que discute la recepción de sus investigaciones, especialmente sobre el de Ciaramitaro y de la Puente Brunke.Véase Tamar Herzog, "Early Modern Citizenship in Europe and the Americas: A Twenty Years Conversation”, Ler História 72 (2021): 225-237, doi: 10.4000/lerhistoria.8495. 
corona española, como los holandeses, ingleses y franceses. Los mismos adjetivos eran usados en el conflicto de tierras entre Chiapan y Zinacantán y en los conflictos por la admisión en la vecindad del reino de Guatemala de los considerados "extranjeros" y "advenedizos".

En relación con esto último, Luis de Estrada presentó otro argumento importante, pues manifestó que los chiapanecos eran "extranjeros de la tierra", por lo que si habían sembrado algunos "pedazuelos" de ella, era porque "habían ido pasando por allí de par, como gente extranjera, y yendo a buscar asiento dónde poblar, como poblaron en el asiento donde presente estaban, que era por camino derecho más de nueve leguas de las dichas tierras que ahora pretendían, en las cuales en ningún tiempo los dichos sus partes habían dejado de sembrar por ser como eran suyas propias habidas desde sus antepasados". ${ }^{33}$ Así, además de argumentar su derecho en función del domino útil, mencionado en la legislación agraria de aquel entonces, también invocaron la precedencia de su posesión. Frente a los argumentos de los zinacantecos, los de Chiapan refirieron también su versión del pasado prehispánico. Su procurador, Juan Martínez, arguyó que los chiapanecas eran "naturales de la dicha Provincia de Chiapa de tiempo inmemorial [...] que había más de mil años que vivían como los demás naturales en la dicha Provincia, y el dicho pueblo había sido siempre y era cabecera de ella, pues de él tomaba nombre la dicha provincia". ${ }^{34}$ Incluso manifestó que la provincia se llamaba Chiapa debido a la "nobleza" del pueblo que era cabecera:

\footnotetext{
El dicho pueblo de Chiapa había sido y era el más noble y de la gente más honrosa y principal de toda la dicha provincia [...]Y que el dicho barrio de Nicoya había salido del dicho pueblo de Chiapa, y no el del como en contrario se decía.Y así los naturales del dicho pueblo como nuestros leales servidores nos habían servido con sus armas y caballos en todo que se habían ofrecido, y que no eran tiranos ni robadores como la parte contraria decía, antes eran gentes muy nobles, y que en lo susodicho era quererlos afrentar e injuriar, antes de alegar de su derecho. ${ }^{35}$
}

Martínez volteó el argumento de los zinacantecos, e incluso el del escudo de armas de la ahora llamada Ciudad Real, pues señalaba que Chiapa de Indios era la cabecera de toda la provincia de Chiapa, es decir, que era capital de la provincia y competía esta posición con la ciudad española. Además, Martínez mencionó que los chiapanecas habían servido con sus armas y caballos en todo lo que se había ofrecido al rey, que eran muy nobles y no habían hecho guerra ni a los españoles ni a otros pueblos. ${ }^{36}$

Se desconoce el resultado del pleito. Lo que interesa aquí es advertir cómo los argumentos jurídicos de las dos repúblicas indias recurrían a una elaboración de la

33. "Extracto de un título antiguo", f. 4.

34. "Extracto de un título antiguo", ff. $5 \mathrm{v}-6$.

35. "Extracto de un título antiguo", f. 6.

36. "Extracto de un título antiguo", f. 6. 
memoria de cada grupo con base en la definición central del usufructo (dominio útil) de tradición romana, llegada a aquellas tierras por vía ibérica. Como en otros casos de discursos sobre la posesión de tierras que invocaban derechos con base en el pasado prehispánico, el pleito entre zinacantecos y chiapanecos, instigado por sus procuradores, que recibían los frutos de sus derechos a explotar la sal, imponía usos sociales específicos del pasado. ${ }^{37}$ En el pleito se reflejaron también los conflictos sociales de la época, tanto los promovidos para delimitar territorios, como los relativos al lugar que ocupaban los considerados "extranjeros y advenedizos" en la provincia de Chiapa, en el reino de Guatemala y en la monarquía de España.

\section{Intentos para revertir la narrativa del "fracaso" desde el "éxito" en la "pacificación" de el Lacandón}

La provincia de Chiapa se configuró como una frontera, ya que desde un inicio los indios de el Lacandón, Pochutla y Topiltepeque resistieron a las "conquistas" y a la imposición del tributo. Durante el siglo XVI, los vecinos hispanos realizaron tres entradas punitivas a esos territorios, con el fin de congregarlos en lugares más accesibles y hacerles tributar. La primera de estas jornadas se realizó en 1559, organizada por la Audiencia de Guatemala y los vecinos de Ciudad Real. Desde la provincia de Chiapa salió el capitán Gonzalo de Ovalle con españoles e indios chiapanecas y zinacantecos, mientras que desde Santiago de Guatemala salieron las huestes capitaneadas por el oidor Pedro Ramírez de Quiñones. La segunda se llevó a cabo después de la labor misionera del dominico fray Pedro Lorenzo de la Nada, en 1586, y fue capitaneada por Juan Morales deVillavicencio, vecino de Ciudad Real. ${ }^{38}$ Una tercera jornada tuvo lugar tres años después, al mando del mismo capitán.

Para aquellas jornadas fue imprescindible la participación de chiapanecas y zinacantecos, por lo que desde 1559 a los indios capitanes de estos contingentes, quienes también habían sido caciques o familia de ellos, se les permitió usar caballos, espadas, arcabuces y dagas. Si bien estas licencias se justificaban en las jornadas de pacificación, los beneficiados mantuvieron su uso cotidiano, que los distinguía de los demás indios. ${ }^{39}$ Esta distinción contribuía a demostrar la calidad social de sus portadores, quienes vestían a la española y practicaban el juego de cañas para diferenciarse de los

37. Por ejemplo, en Metztitlán. Véase Jaime J. Lacueva Muñoz y Caroline Cunill, "La negociación indígena frente al afianzamiento económico hispano: la defensa de las minas de alumbre de Metztitlán en el siglo XVI", El municipio indiano: relaciones interétnicas, sociales y económicas. Homenaje a Luis Navarro García, coords. Manuela Cristina García Bernal y Sandra Olivero Guidobono (Sevilla: Universidad de Sevilla, 2009) 39-58.

38. Jan de Vos, La paz de Dios y del Rey. La conquista de la Selva Lacandona (1525-1821) (México: Fondo de Cultura Económica, 1996) 87; Laura Caso Barrera, Caminos en la selva. Migración, comercio y resistencia. Mayas yucatecos e itzaes, siglos XVII-XIX (México: El Colegio de México / Fondo de Cultura Económica, 2002).

39. Sobre el discurso de la frontera utilizado por caciques chontales, véase Caroline Cunill, "La frontera en el discurso de los caciques chontales, siglo XVI", Poblar la inmensidad: sociedades, conflictividad y representación en los márgenes del Imperio Hispánico (siglos XV-XIX), coord. Salvador 
indios tamemes, de los macehuales que trabajan en las milpas, los trapiches e ingenios azucareros pertenecientes a vecinos hispanos y a frailes dominicos. ${ }^{40}$

Estas prácticas de distinción social por parte de los caciques chiapanecas no eran bien vistas por algunos vecinos de Ciudad Real ni por el alcalde mayor, Juan de Mesa y Altamirano, ferviente opositor de los frailes dominicos establecidos en Chiapa de Indios. ${ }^{41}$ El 23 de noviembre de 1580, Mesa y Altamirano recibió información sobre una estancia de ganado mayor y menor de la "comunidad del pueblo y de los propios del pueblo" que las autoridades de Chiapan vendieron al albañil portugués Diego de Seijas, "hombre pobre", quien, a su vez, las había donado al Monasterio de Santo Domingo de Chiapan. La misma información acusaba a los alcaldes ordinarios y regidores chiapanecas por vender gran cantidad de ovejas de la misma estancia a Bazquianes de Pereyra, vecino de Ciudad Real. En estas acusaciones, se incluían otras sobre malos tratos a los indios del común. ${ }^{42}$

El alcalde mayor determinó enviar al fiel ejecutor de Ciudad Real, Pedro de Estrada, como juez de comisión para visitar el pueblo de Chiapan e impartir justicia. Para su mala fortuna, la llegada del comisionado local coincidió con la visita que realizaba el receptor de la Real Audiencia de Guatemala, Alonso Rodríguez, invitado por el alcalde chiapaneca Alonso Chocanu. La presencia del enviado de la Audiencia eclipsó al comisionado del alcalde mayor, por lo que el cabildo indígena no le reconoció. ${ }^{43}$

Según el testimonio de Pedro de Estrada, alrededor de 400 chiapanecas lo esperaban en el patio de las casas reales de Chiapan para matarlo, por lo que prefirió volverse a Ciudad Real sin cumplir el objetivo de su comisión. Estos hechos fueron considerados como un motín contra el alcalde mayor, quien emitió un bando contra el derecho al uso de armas que ejercían los indios chiapanecas. En el documento, el alcalde refirió que el pueblo de Tlaxcala era "más principal y más

Bernabéu Albert (Sevilla: Consejo Superior de Investigaciones Científicas / Ediciones Rubeo, 2010) 209-230.

40. Mario Humberto Ruz Sosa, Savia india, floración ladina. Apuntes de una historia de las fincas comitecas (siglos XVIII y XIX) (México: Consejo Nacional para la Cultura y las Artes, 1992) 74-79.

41. Sobre los conflictos que había entre los frailes dominicos y el alcalde mayor Juan de Mesa Altamirano, véanse Lenkersdorf, Repúblicas de indios; Laura García Catarino, "Petición de funcionarios y religiosos en la segunda mitad del siglo XVI: justicia para los indios!”, De Mérida a Taguzgalpa. Seráficos y predicadores en tierras mayas, chiapanecas y xicaques, coord. José Manuel Chávez Gómez (México: Secretaría de Cultura / Instituto Nacional de Antropología e Historia, 2017) 97119; Virginia Margarita López Tovilla, "Contra el alcalde mayor, don Juan de Meza Altamirano, por haber contravenido a la prohibición que hizo su señoría ilustrísima sobre enmascarados", EntreDiversidades. Revista de Ciencias Sociales y Humanidades 1.2 (2014): 207-252, doi: 10.31644/ ED.2.2014.d01.

42. "Contra los indios de Chiapan y sobre la venta de estancias", Ciudad Real de Chiapa, 1582.AGI, Sevilla, Audiencia de Guatemala, leg. 56, f. 135.

43. "Testimonio de Pedro de Estrada de lo que sucedió en el pueblo de Chiapan", Ciudad Real de Chiapa, 1582. AGI, Sevilla, Audiencia de Guatemala, leg. 56, f. 137v. 
servidor de su majestad" que el de Chiapan, ${ }^{44}$ ello le ayudaba a argumentar que, aun en tales circunstancias, los tlaxcaltecas no usaban armas, por estar prohibidas para los indios, lo que los chiapanecas no acataban. ${ }^{45}$

Las prohibiciones detonaron nuevas solicitudes de licencias que dieron pie a probanzas de méritos y servicios para solicitar privilegios al rey o a sus representantes en la Audiencia de Guatemala. Así lo hicieron Bernabé Guerra y Rodrigo de León, indios de Chiapan, quienes, en 1603, incluyeron en sus peticiones para usar armas y caballos la solicitud de ayuda para sustentar a su familia y exentar del tributo a sus hijos. ${ }^{46}$

Para fortalecer sus solicitudes, los chiapanecas refirieron los hechos de sus antepasados y las de ellos mismos para probar al rey su fidelidad y servicio, con el fin de pedir contraprestaciones. Don Bernabé Guerra presentó los traslados de títulos y nombramientos de gobernador otorgados a sus parientes; empezando por el de su abuelo, don Pedro Noti, quien obtuvo el nombramiento de cacique de Chiapan como resultado de la negociación con el encomendero Baltasar Guerra después de la rebelión del Sumidero. ${ }^{47}$ La probanza del descendiente chiapaneca cargaba los signos del pasado cooperador de su abuelo. Si la alianza de Pedro Noti con los dominicos frente a los encomenderos y el cabildo de Ciudad Real le había reportado la pérdida temporal del cacicazgo en 1546, también le había valido la defensa de fray Bartolomé de las Casas, quien consiguió para el chiapaneca una provisión real firmada por el príncipe Felipe para que se le reintegrara el cacicazgo. ${ }^{48}$

Más cerca en el tiempo, Bernabé Guerra informó que, en 1583, él y su padre, a quien bautizaron con el nombre del encomendero Baltasar Guerra, participaron en la jornada de Lacandón "con sus armas y caballos a su costa”, capitaneando a los indios chiapanecas aliados de la expedición. Aunque el viejo encomendero regresó a la Península Ibérica, los descendientes de Noti continuaron usando el apellido Guerra como signo de la antigüedad de su colaboración con los españoles, a la que

44. Los superlativos utilizados para caracterizar a los tlaxcaltecas provenían de su participación en las diferentes entradas de conquista: México Tenochtitlán, las conquistas del norte y las que realizaron en el sureste y Centroamérica. En recompensa, el rey no los encomendó a ningún español y los reconoció como una ciudad con ciertos privilegios.Véase Jovita Baber, "Categories, Self-Representation and the Construction of the Indios", Journal of Spanish Cultural Studies 10.1 (2009): 27-41.

45. "Contra los indios de Chiapan", ff. 136-137.

46. "Solicitud de don Rodrigo de León para una ayuda de costas y licencia para usar caballos de rua, espada y armas, además de que sus hijos no paguen el tributo", Santiago de Guatemala, 2 de diciembre de 1603. AGI, Sevilla, Audiencia de Guatemala, leg. 59; "Solicitud de don Bernabé Guerra para una ayuda de costas y licencia para usar caballos de rua, espada y armas, además de que sus hijos no paguen el tributo", Santiago de Guatemala, 8 de diciembre 1603. AGI, Sevilla, Audiencia de Guatemala, leg. 59.

47. Sobre la rebelión del Sumidero, véase De Vos, La batalla del Sumidero.

48. "Traslado de la cédula real enviada por el príncipe Felipe sobre lo sucedido a don Pedro Noti", Ciudad Real de Chiapa, 2 de julio de 1547. AGI, Sevilla, Audiencia de Guatemala, leg. 59, f. 4. Sobre el conflicto por el cacicazgo de Chiapan y la participación de los frailes dominicos en este, véase Bahena Pérez, "La participación de frailes dominicos". 
se sumaron las alianzas con los dominicos, lo que probaba, desde su óptica, la continuada fidelidad a la Corona que les permitía solicitar mercedes. ${ }^{49}$

Por su parte, el chiapaneca Rodrigo de León, en sus probanzas para usar armas y caballo, recordaba las de su padre, Luis de León Cabeza de Vaca, y su abuelo, Diego Nocayola, quienes habían colaborado en la pacificación de los alzamientos de la región, en los que el último fue muerto mientras defendía la posición de los españoles. Los servicios les habían valido el reconocimiento del virrey Antonio de Mendoza, quien los distinguió con licencias para andar a caballo y portar armas, como si fueran conquistadores. ${ }^{50}$

Como era usual, a la hora de buscar la gracia real, los méritos se acumulaban por generaciones. Tanto Bernabé Guerra como Rodrigo de León aludieron a los servicios de sus antepasados haciéndolos suyos. Se mostraron como aprendices de sus padres y abuelos para formarse como leales vasallos y súbditos del rey. Empleaban la idea de "imitación" como el dispositivo retórico por el que se transmitía el mérito y, con ello, el derecho a la gracia. Así, el escribano de Rodrigo de León establecía el mecanismo por el cual las mercedes pasadas debían actualizarse:

Imitando al suyo sirvió a vuestra majestad en todo lo que en el dicho pueblo se refiere, y fue alcalde ordinario y regidor y tuvo otros oficios honrosos y fueron uno de los capitanes que fueren a la pacificación del lacandón, e Pochutla, e Topiltepeque [...] Poniéndose en los mayores peligros de la guerra que hubo hallándose en ella con su gente a su costa en que gastó lo que tenía.Y que don Juan su hermano y tío del dicho don Rodrigo falleció sirviendo en la dicha ocasión de una herida que le dieron los indios de la dicha Pochutla.Y al dicho don Luis su padre se le dio licencia por el licenciado Axcoeta, oidor de Guatemala cuando visitó aquella provincia para tener arcabuz con sus aderezos y andar con el por las partes que le pareciese, y el presidente Valverde para andar en caballo con silla y freno. Que el dicho don Rodrigo imitando a su padre, aguelo y tío sirvió con sus armas y caballos a sus costas en la jornada del Lacandón que estaban rebelados los indios acudiendo a todo con fidelidad y por costarle de ello al doctor Sande le dio licencia para andar a caballo con silla y freno y hacer y tener caballos de rua y de camino. ${ }^{51}$

La "imitación" de los vasallos en el servicio al rey, al tiempo que esperaba la correspondiente imitación de las autoridades reales, les sirvió a los solicitantes para revertir el mote de "indios de guerra" que ensombrecía al pueblo entero. De esta manera se configuraron como una familia de autoridades indígenas, capitanes de "pacificación" y como "nobles", al usar armas y caballos. Rodrigo de León trasladó las probanzas que hizo su padre tanto en Ciudad Real el 17 de febrero de 1576, como en el pueblo de Chiapa de Indios, en 1579. Para las primeras, Luis de León presentó cuatro testigos, quienes eran vecinos prominentes de Ciudad Real y

49. Sobre la elección de continuar o cambiar de apellidos en la época moderna, véase Tamar Herzog,

"Nombres y apellidos: ¿cómo se llamaban las personas en Castilla e Hispanoamérica durante la época moderna?”, Jahrbuch für Geschichte Lateinamerikas 44 (2007): 9.

50. "Solicitud de don Rodrigo de León”, f. 2.

51. "Solicitud de don Rodrigo de León”, f. 2. 
participaron en la "pacificación” de Lacandón, Pochutla y Topiltepeque en 1556. Entre estos, se encontraba el regidor, juez de bienes difuntos Diego de Trejo, quien fue alférez durante dicha jornada y vio a Luis de León entre los 400 chiapanecas, sobre el que afirmó que se encontraba entre:

los que mejor e mas bien sirvieron a su majestad, porque se alzaron todos los chiapanecas en la laguna del lacandón e fueron nadando más de una legua al peñol [donde estaban los lacandones] con sus armas arcos y flechas, por causa que no había canoas ni bergantines, e porque razón sabe el servicio que hizo a su majestad entrando e nadando en la dicha laguna e se pusieron en gran peligro de sus vidas. ${ }^{52}$

Por su parte, Bernabé Guerra informó que, como él y su padre, Baltasar Guerra, participaron en la "pacificación" de Lacandón, el 19 de marzo de 1589 el capitán español Juan de Morales Villavicencio en el pueblo de Ocosingo "de la frontera" les dio licencia para usar "arcabuz, su espada y daga y andar a caballo con silla y freno". ${ }^{33}$ Rodrigo de León también aludió a las licencias que se le hicieron a su padre y abuelo para usar caballo y armas. ${ }^{54}$

Los Guerra y los León formaron parte de los 12 indios a los que la Audiencia de Guatemala permitió usar armas y andar a caballo. La justificación que dieron era que habían servido "personalmente con sus armas y caballos que compraron a su costa sin llevar sueldo e interés alguno" lo que habían hecho tanto en la jornada de el Lacandón en 1586 y en la de $1589 .{ }^{55}$ De esta manera, en la documentación generada por la autoridad real tanto a Bernabé Guerra como a Rodrigo de León, se les comparó con soldados españoles. Sin embargo, esto no quiso decir que se les considerara en igualdad de condiciones que a un español, ${ }^{56}$ pues en cualquier momento se les podría

52. "Testificación de Diego de Trejo para las probanzas de méritos y servicios de Luis de León Cabeza deVaca", pueblo de Chiapan, 17 de febrero de 1578. AGI, Sevilla, Audiencia de Guatemala, leg. 59, ff. 7r-7v. Esto fue avalado por los vecinos de Ciudad Real: Juan Muñóz Talavera y el maestre Diego Ramírez. “Testificación de Juan Muñoz Talavera para las probanzas de méritos y servicios de Luis de León Cabeza de Vaca”, Ciudad Real de Chiapa, 17 de febrero de 1578. AGI, Sevilla, Audiencia de Guatemala, leg. 59, f. 11v; "Testificación de Diego Ramírez para las probanzas de méritos y servicios de Luis de León Cabeza de Vaca", Ciudad Real de Chiapa, 17 de febrero de 1578. AGI Sevilla, Audiencia de Guatemala, leg. 59, ff. 9-10v.

53. "Traslado de la licencia que otorgó Juan de Morales de Villavicencio a don Bernabé Guerra y a don Baltasar Guerra", pueblo de Ocosingo, 19 de marzo de 1589. AGI, Sevilla, Audiencia de Guatemala, leg. 59, ff. 4r-4v.

54. "Juan Morales de Villavicencio que se le de licencia a Rodrigo de León para usar caballo", Ciudad Real de Chiapa, 23 de julio de 1589. AGI, Sevilla, Audiencia de Guatemala, leg. 59, f. 15v.

55. "Provisión de la Audiencia de Guatemala para que el capitán Juan Morales de Villavicencio pueda dar licencia a doce indios principales para andar a caballo", pueblo de Ocosingo, 22 de diciembre de 1590. AGI, Sevilla, Audiencia de Guatemala, leg. 59, ff. 5v-6.

56. Este planteamiento ha sido estudiado por Gabriela Ramos para Perú. Véase Gabriela Ramos, "El rastro de la discriminación. Litigios y probanzas de caciques en el Perú colonial temprano", Fronteras de la Historia 21.1 (2016): 71. 
cobrar el tributo o solicitar otro tipo de trabajos, como se exigió a los indios mexicanos de Ciudad Vieja en Guatemala. ${ }^{57}$ Las solicitudes de estos personajes muestran la necesidad que tenían por distinguirse del común del pueblo, lo que hacía evidente la desigualdad social que había al interior de Chiapan entre los indios considerados caciques y principales y la población en general. También denota que estos indios querían destacarse como vasallos y súbditos del rey español, por lo que hacían notar su participación en las jornadas de "pacificación" a partir del uso de caballos y armas, además de celebrar juegos de cañas en el pueblo. Es decir, por un lado, se asumieron con la categoría jurídica de indios para obtener protección y los derechos que ello les daba, y por el otro, se distinguieron socialmente del común del pueblo. ${ }^{58}$

Esta distinción estaba relacionada con la formación de un discurso, en el que se legitimaba a quienes pertenecían a las familias de "caciques" de la primera mitad del siglo XVI para ocupar los cargos de república. Mientras, a los indios del común que no pertenecían a estas familias se les marginaba del cabildo. Tanto Bernabé Guerra como Rodrigo de León aludieron a la participación que tuvieron sus padres y abuelos como autoridades indígenas del pueblo de Chiapan. Por ejemplo, Bernabé Guerra mostró el nombramiento que el presidente de la Audiencia de Guatemala, Mallen de Rueda, hizo a su padre como gobernador del pueblo el 5 de diciembre de 1590, en el que se argumentaba que este era "indio natural del dicho pueblo e principal y buen cristiano, de buenas costumbres, capaz para el dicho oficio". ${ }^{59}$ La evangelización era clave en las aspiraciones de los indios a cargos de autoridad reconocidos por la Corona. ${ }^{60}$

Según la información presentada por su descendiente, a Baltasar Guerra se le prorrogó por cuatro años más el nombramiento de gobernador, hasta 1596, cuando murió y fue sustituido por Tomás de León, quien gobernó hasta 1602 por estar muy enfermo. ${ }^{61}$ En ese año, el procurador general del cabildo de Chiapa de Indios, Fernando de Sosa, expresó el supuesto interés del pueblo en que Bernabé Guerra fuera su gobernador. El argumento era que este indio principal era hijo de Baltasar Guerra, y además se dijo que "acudió a recoger a los religiosos cuando comenzaron a plantar y predicar el Santo Evangelio", lo que fue apoyado por fray Rafael de Luján, prior provincial de la orden de Santo Domingo en Chiapan. ${ }^{2}$ Esto demuestra el aval que tenían estas familias de caciques y principales de las autoridades religiosas, el cual se fraguó desde la llegada de los dominicos al pueblo en 1545.

57. Matthew 128.

58. Baber 37.

59. "El gobernador y presidente de la Audiencia de Guatemala Pedro Mallén de Rueda nombra a don Baltasar Guerra como gobernador”, Santiago de Guatemala, 5 de diciembre de 1590. AGI, Sevilla, Audiencia de Guatemala, leg. 59, ff. 5v-6.

60. Ramos 78.

61. "Prórroga para don Baltasar Guerra hasta 1596", pueblo de Chiapa, 12 de septiembre de 1595. AGI, Sevilla, Audiencia de Guatemala, leg. 59, ff. 9v-10.

62. "Nombramiento de gobernador a Bernabé Guerra”, pueblo de Chiapa, 16 de octubre de 1602. AGI, Sevilla, Audiencia de Guatemala, leg. 59, ff. 10v-11. 
Por su parte, Rodrigo de León mostró cómo su padre fue alcalde ordinario, regidor y procurador del pueblo a partir de las probanzas de méritos y servicios que hizo en 1579, en donde fueron testigos los indios que integraban el cabildo. ${ }^{63}$ En estas, se decía que Luis de León era hijo de Diego Nocayola, cacique y principal, y su madre era Juana. Según estas probanzas, al morir Diego Nocayola, Luis de León quedó encargado con don Pedro Noti, cacique, quien le sustentó y ayudó a reparar sus casas. ${ }^{64}$ Ahora bien, tanto Bernabé Guerra como Rodrigo de León pertenecían a la misma facción dentro de la república de indios, y se coordinaron estratégicamente la realización de sus probanzas para solicitar conjuntamente las licencias para utilizar armas y caballo, adquirir ayudas de costas y para que sus descendientes no pagaran tributos. Además, el 8 de abril de 1603, nombraron sus procuradores a los frailes Alonso García, prior del Convento de Zacapulas, y a Juan Luengo, quienes representaron a Bernabé Guerra y a Rodrigo de León ante el Consejo del rey Felipe III para negociar sus correspondientes solicitudes. ${ }^{65}$

En ambas probanzas, don Bernabé Guerra y don Rodrigo de León se identificaron como indios "pacificadores" y narraron los éxitos que lograron junto con sus padres en la jornada de Lacandón. Además, mencionaron que las autoridades reales los reconocieron como autoridades del pueblo. En estos documentos se muestra la voluntad de estos indios por distinguirse de los indios del común y presentarse como los más fieles vasallos del rey en Chiapan.

Si la retórica de fidelidad familiar reportaba a los descendientes de los señores chiapanecas soluciones exitosas para sus peticiones, era porque en esos servicios descansaba la legitimidad de la autoridad real en aquel pueblo. Con sus solicitudes, contribuían a consolidar el orden de la monarquía a escala local. Para el siglo XVII, la cabecera de los chiapanecas fue considerada una ciudad, conocida como Chiapa de Indios, con lo que borraba el pasado insumiso que la marcó la centuria precedente. En alguna medida, las retóricas familiares de los 12 solicitantes de finales del XVI, principalmente las de Bernabé Guerra y Rodrigo León, sentaron las bases individuales de esta transformación colectiva.

\section{Conclusiones}

A partir del análisis de los pleitos por encomiendas, de la descripción del escudo de armas de Ciudad Real y de los litigios de tierras entre Chiapan y Zinacantán,

63. "Testificación de Diego Ramírez para las probanzas de méritos y servicios de Luis de León Cabeza de Vaca", Ciudad Real de Chiapa, 17 de febrero 1578. AGI, Sevilla, Audiencia de Guatemala, leg. 59, f. 11.

64. "Probanzas de méritos y servicios de Luis León Cabeza de Vaca", pueblo de Chiapa, 1579. AGI, Sevilla, Audiencia de Guatemala, leg. 59, f. 19v.

65. "Bernabé Guerra nombra sus procuradores al prior del Convento de Zacapulas fray Alonso García y a fray Juan Longo", pueblo de Chiapa, 9 de abril de 1603. AGI, Sevilla, Audiencia de Guatemala, leg. 59, f. 11v; "Poder que dio Rodrigo de León a los frailes Alonso García y Juan Luengo", pueblo de Chiapa, 9 de abril de 1603. AGI, Sevilla, Audiencia de Guatemala, leg. 59, f. 27. 
conquistadores y vecinos españoles calificaron a los chiapanecas como "indios de guerra" e "indios de paz", como "bellacos" y "gente sin razón", o "advenedizos" y "extranjeros". Los chiapanecas que pertenecían a las familias de caciques buscaron revertir estas categorías a partir de narrativas que referían al pasado prehispánico, al momento de la conquista de los Altos de Chiapas y a la pacificación de Lacandón. Así, contrapusieron la categoría de "indio rebelde" a la de "indio pacificador", o las de "extranjero" y "advenedizo" a las de "nobles y naturales de la provincia de tiempo inmemorial". Además, buscaron comprobar que las salinas de Iztapa les correspondían por el usufructo que hacían de ellas y por los títulos que les otorgaron las autoridades del cabildo de Ciudad Real y de la Audiencia de Guatemala.

A diferencia de los documentos producidos por los vecinos españoles de Ciudad Real, en las probanzas de los méritos y servicios realizadas por los caciques y principales de Chiapa de Indios, se observa la necesidad que tenían de distinguirse como leales vasallos y súbditos del rey. En ellas hicieron de su hispanización una herramienta para sobrevivir como autoridades indígenas en el contexto de configuración de las repúblicas de indios, en donde el servicio del rey, su cristianización y su participación en la "pacificación” de Lacandón como capitanes fueron prácticas y narraciones que les distinguieron de aquellos indios considerados "del común del pueblo”. En este caso, el discurso de frontera generó diferencias sociales en la provincia y específicamente en el pueblo de Chiapa de Indios.

Los caciques y principales chiapanecas hicieron suyas las prácticas de la justicia hispana para defenderse de las narrativas de sus contrincantes. Así, el uso del pasado fue producto del conflicto y la negociación en los que se reconfiguró la sociedad indígena de Chiapa de Indios durante la segunda mitad del siglo XVI y principios del XVII.

\section{Fuentes}

\section{Manuscritas}

Archivo Duque de Alva, Madrid (ADA)

Escudos de Armas

Archivo General de Centro América, Guatemala (AGCA)

Tierras

Archivo General de Indias, Sevilla (AGI)

Audiencia de Guatemala

Justicia

\section{Impresas}

Díaz del Castillo, Bernal. Historia verdadera de la conquista de la Nueva España (Manuscrito Guatemala). Ed. José Antonio Barbón Rodríguez. México: El Colegio de México / Universidad Nacional Autónoma de México / Servicio Alemán de Intercambio Académico, 2005. 
López Tovilla,Virginia Margarita. "Contra el alcalde mayor, don Juan de Meza Altamirano, por haber contravenido a la prohibición que hizo su señoría ilustrísima sobre enmascarados". EntreDiversidades. Revista de Ciencias Sociales y Humanidades 1.2 (2014): 207-252. Doi: 10.31644/ED.2.2014.d01.

\section{Bibliografía}

Baber, Jovita. "Categories, Self-Representation and the Construction of the Indios". Journal of Spanish Cultural Studies 10.1 (2009): 27-41.

Bahena Pérez, Martha Atzin. “El mundo en el reino de Guatemala: 'extranjeros', arraigo y cohesión social 1535-1630”. Tiempos Modernos 11.42 (2021): 220-237.

"La participación de frailes dominicos en la rebelión chiapaneca de 1547". De Mérida a Taguzgalpa. Seráficos y predicadores en tierras mayas, chiapanecas y xicaques. Coord. José Manuel A. Chávez Gómez. México: Secretaría de Cultura / Instituto Nacional de Antropología e Historia, 2017.

Barrera, Caso. Caminos en la selva. Migración, comercio y resistencia. Mayas yucatecos e itzaes, siglos XVII-XIX. México: El Colegio de México / Fondo de Cultura Económica, 2002.

Bloch, Marc. Historia e historiadores. Madrid:Akal, 2008.

Burke, Peter. Formas de historia cultural. Madrid: Alianza Editorial, 2000.

Carrera Quezada, Sergio Eduardo. Sementeras de papel. La regularización de la propiedad rural en la Huasteca Serrana, 1550-1720. México: El Colegio de México / Centro de Investigaciones y Estudios Superiores en Antropología Social, 2018.

. "Las composiciones de tierras en los pueblos de indios en dos jurisdicciones coloniales de la Huasteca, 1692-1720". Estudios de Historia Novohispana 52 (2015): 29-50.

Carzolio, María Inés. "En los orígenes de la ciudadanía en Castilla. La identidad política del vecino durante los siglos XVI y XVII". Hispania 62.211 (2002): 637-691. Doi: 10.3989/hispania.2002.v62.i211.262.

Ciaramitaro, Fernando y José de la Puente Brunke. Coords. Extranjeros, naturales y fronteras en la América Ibérica y Europa (1492-1830). México / Murcia: Universidad Autónoma de la Ciudad de México / Editorial de la Universidad de Murcia / Red Columnaria, 2017.

Cunill, Caroline. Los defensores de indios de Yucatán y el acceso de los mayas a la justicia colonial, 1540-1600. Mérida: Centro Peninsular en Humanidades y Ciencias Sociales / Universidad Nacional Autónoma de México, 2012. . "La frontera en el discurso de los caciques chontales, siglo XVI". Poblar la inmensidad: sociedades, conflictividad y representación en los márgenes del Imperio Hispánico (siglos XV-XIX). Coord. Salvador Bernabéu Albert. Sevilla: Consejo Superior de Investigaciones Científicas / Ediciones Rubeo, 2010.

De Vos, Jan. Vivir en frontera. La experiencia de los indios de Chiapas. México: Centro 
de Investigaciones y Estudios Superiores en Antropología Social / Instituto Nacional Indigenista, 1997.

. La paz de Dios y del Rey. La conquista de la Selva Lacandona (1525-1821). México: Fondo de Cultura Económica, 1996.

. La batalla del Sumidero. Historia de la rebelión de los chiapanecas, 1524-1534, a través de testimonios españoles e indígenas. México: Instituto Nacional Indigenista / Consejo Nacional para la Cultura y las Artes, 1990.

García Catarino, Laura. "Petición de funcionarios y religiosos en la segunda mitad del siglo XVI: justicia para los indios!”. De Mérida a Taguzgalpa. Seráficos $y$ predicadores en tierras mayas, chiapanecas y xicaques. Coord. José Manuel Chávez Gómez. México: Secretaría de Cultura / Instituto Nacional de Antropología e Historia, 2017.

Gerhard, Peter. La frontera sureste de la Nueva España. México: Universidad Nacional Autónoma de México, 1991.

Halbwachs, Maurice. La memoria colectiva. Zaragoza: Prensas Universitarias de Zaragoza, 2004.

. Les cadres sociaux de la mémoire. París: Librairie Félix Alcan, 1925.

Herzog, Tamar. "Early Modern Citizenship in Europe and the Americas: A Twenty Years' Conversation”. Ler História 72 (2021): 225-237. Doi: 10.4000/ lerhistoria.8495.

. "Naturales y extranjeros: sobre la construcción de categorías en el mundo hispánico”. Cuadernos de Historia Moderna, Anejo 10 (2011): 21-31. Doi: 10.5209/rev_CHMO.2011.38668.

. "Nombres y apellidos: ¿cómo se llamaban las personas en Castilla e Hispanoamérica durante la época moderna?”. Jahrbuch für Geschichte Lateinamerikas 44 (2007): 1-35.

Hespanha, Antonio Manuel. "Categorias. Uma reflexão sobre a prática de classificar”. Análise Social 38.168 (2003): 823-840.

Lacueva Muñoz, Jaime J. y Caroline Cunill. "La negociación indígena frente al afianzamiento económico hispano: la defensa de las minas de alumbre de Metztitlán en el siglo XVI". El municipio indiano: relaciones interétnicas, sociales y económicas. Homenaje a Luis Navarro García. coords. Manuela Cristina García Bernal y Sandra Olivero Guidobono. Sevilla: Universidad de Sevilla, 2009.

Lenkersdorf, Gudrun. Repúblicas de indios. Pueblos mayas en Chiapas, siglo XVI. México: Plaza y Valdés, 2010.

Génesis histórica de Chiapas 1522-1532. El conflicto entre Portocarrero y Mazariegos. México: Universidad Nacional Autónoma de México, Instituto de Investigaciones Filológicas, 1993.

Mayer, Frederick W. Narrative Politics. Stories and Collective Action. Oxford: Oxford University Press, 2014.

Macleod, Murdo J. Historia socio-económica de la América Central Española, 15201720. Guatemala: Editorial Piedra Santa, 1980. 
Matthew, Laura E. Memorias de conquista. De conquistadores indígenas a mexicanos en la Guatemala colonial. Puebla / Tlaxcala / Ciudad de Guatemala: Instituto de Ciencias Sociales y Humanidades “Alfonso Vélez Pliego”, Benemérita Universidad Autónoma de Puebla / Sociedad de Geografía, Historia, Estadística y Literatura del Estado de Tlaxcala / Centro de Estudios Urbanos y Regionales, Universidad de San Carlos Guatemala, 2017.

Matthew, Laura E. y Michel R. Oudijk. Eds. Indian Conquistadors. Indigenous Allies in the Conquest of Mesoamerica. Norman: University of Oklahoma Press, 2012.

Menegus Bornemann, Margarita. "El gobierno de los indios en la Nueva España, siglo XVI. Señores o cabildo”. Revista de Indias 59.217 (1999): 599-617.

Navarrete Cáceres, Carlos Alberto. The Chiapanec History and Culture. Provo: Brigham Young University, 1966.

Nora, Pierre. Les lieux de mémoire. Montevideo: Ediciones Trilce, 2008.

Peset, Mariano, y Margarita Menegus. "Rey propietario o rey soberano". Historia Mexicana 43.4 (1994): 563-599.

Ramos, Gabriela. "El rastro de la discriminación. Litigios y probanzas de caciques en el Perú colonial temprano”. Fronteras de la Historia 21.1 (2016): 64-88.

Ruz Sosa, Mario Humberto. Mohonyhovi. Sanctissima Trinidad... Chiapa y su Cofradía de la Vera Cruz al mediar el siglo XVII. México: Universidad Nacional Autónoma de México, Instituto de Investigaciones Filológicas, 2020. - Savia india, floración ladina. Apuntes de una historia de las fincas comitecas (siglos XVIII y XIX). México: Consejo Nacional para la Cultura y las Artes, 1992.

Sorgentini, Hernán. "Reflexión sobre la memoria y autorreflexión de la historia”. Revista Brasileira de História 23.45 (2003): 103-128.

Sullón Barreto, Gleydi. Extranjeros integrados. Portugueses en la Lima virreinal, 15701680. Madrid: Consejo Superior de Investigaciones Científicas, 2016.

Viegas, Josefa. "Memoria e historia. Los usos sociales del pasado". Teoría y Praxis 10 (2007): 109-121.

Zavala, Silvio. Los esclavos indios en Nueva España. México: El Colegio Nacional, 1967. 